\title{
QUESTÕES CONTROVERTIDAS SOBRE CONCILIAÇÃO E MEDIAÇÃO NO ÂMBITO DAS SERVENTIAS NOTARIAIS E DE REGISTROS
}

\section{ARTIGO ORIGINAL}

MELO, Magaly Abreu De Andrade Palhares De ${ }^{1}$, CALDAS, Camilo Onoda Luiz ${ }^{2}$

MELO, Magaly Abreu De Andrade Palhares De. CALDAS, Camilo Onoda Luiz. Questões controvertidas sobre conciliação e mediação no âmbito das serventias notariais e de registros. Revista Científica Multidisciplinar Núcleo do Conhecimento. Ano 06, Ed. 06, Vol. 04, pp. 05-28. Junho de 2021. ISSN: 2448-0959, Link de acesso: https://www.nucleodoconhecimento.com.br/semcategoria/conciliacao-e-mediacao, DOI: 10.32749/nucleodoconhecimento.com.br/lei/conciliacao-e-mediacao

\section{RESUMO}

A proposta de estudo surgiu como atividade da disciplina "Meios Consensuais de Composição de Conflitos e sua Contestação Judicial", como requisito do Programa de Mestrado de Direito Empresarial realizado pela Escola Paulista de Direito (EPD). O objetivo do estudo foi o de analisar as contendas apresentadas pela efetuação da política que disciplina a inserção da conciliação e mediação através da

${ }^{1}$ Mestranda em Direito - Soluções alternativas de controvérsias empresariais pela Escola Paulista de Direito - EPD, Pós-graduada em Métodos Adequados em Resolução de Conflitos pelo Instituto Brasiliense de Direito Público - IDP, Graduação em Direito pela Centro Universitário de Brasília - UniCEUB.

${ }^{2}$ Orientador. Doutorado em Direito. 
regulamentação do artigo 42 da Lei de Mediação (Lei 13.140/2015) pelo Provimento 67 de 26 de março de 2018 do Conselho Nacional de Justiça (CNJ) quanto à inserção desses métodos na esfera dos cartórios extrajudiciais. O trabalho examina os seguintes temas: a atuação, capacitação e a falta de uma política institucional uniforme, o rompimento do princípio da confidencialidade, a representação por procuração, a impossibilidade de requerimento de resolução de conflitos familiares, os reflexos da devida homologação judicial de acordos extrajudiciais, a necessidade de previsão legal para cobrança de valores e a falta de unificação de remuneração. Prossegue então, formulando propostas tendentes ao aperfeiçoamento da práxis, trazendo as conclusões pertinentes em termos de adequações para utilização da conciliação e mediação pelos cartórios extrajudiciais de uma forma mais eficaz e produtiva.

Palavras Chaves: Conciliação, Mediação, Controvérsias, Serventia notarial e de registros.

\section{INTRODUÇÃO}

Conjetura-se que os métodos adequados de resolução de conflitos emergiram na sociedade devido ao crescimento econômico do país combinado com a dificuldade de obter decisões rápidas e definitivas do Estado-juiz. A investigação constante por um melhor acesso à justiça fez com que mecanismos paralelos fossem amplamente considerados, dentre eles a conciliação e a mediação, com emprego cada vez mais presente no seio da sociedade contemporânea no sentido de oferecer uma resolução mais adaptada para a maioria dos conflitos sociais apresentados.

Ademais a chamada desjudicialização com a proposta de redução da burocracia e de formalidades para alguns atos, bem como a celeridade de resolução de conflitos, combinada com a expectativa de redução das demandas no judiciário foram com certeza um impulso para que surgisse uma política para implementar a utilização da 
conciliação e mediação no âmbito das serventias notariais e de registros na sociedade brasileira em consonância com o que está acontecendo a nível mundial.

Em consonância com o relato anterior, a Lei 13.140/2015, Lei de Mediação, em seu artigo 42 trouxe prevista que a função de mediação/conciliação poderia ser exercida também pelos cartórios extrajudiciais e como esse assunto não estava disciplinado, o Conselho Nacional de Justiça (CNJ) complementou a norma através do provimento $N^{\circ}$ 67/2018 que disciplinou a atividade cartorária no exercício da mediação e conciliação conforme o caso.

O provimento $N^{\circ} 67 / 2018$ do $\mathrm{CNJ}$ e a Lei de mediação regulamentam, no âmbito das serventias notariais, a conciliação e a mediação, amparado pela ideia de mudança de paradigma trazida pela política nacional ampliando assim os tipos de serviços oferecidos para a sociedade no geral.

Importante salientar que o provimento $N^{\circ} 67 / 2018$ surge de uma sequência de atos legislativos envolvendo a política nacional de tratamento adequado de conflitos iniciada pelo CNJ em 2010 onde através da Resolução 125 instituiu-a, inclusive trazendo para o âmbito do poder judiciário a responsabilidade por também implementá-la e a partir desse momento a Resolução veio por inspirar a reforma do código de processo civil que teve sua conclusão em 2015, a Lei de Mediação que foi também concluída em 2015 e a Lei de Arbitragem, Lei № 9.307/1996, que foi atualizada pela Lei № 13.129 de 2015 promovendo, assim, a formação de um microssistema de meios adequados de resolução de conflitos.

Dessa forma, o microssistema de meios adequados de resolução de conflitos tem amparo central no artigo $3^{\circ}$, $2^{\circ}$, do Código de Processo Civil que traz que "o Estado promoverá, sempre que possível, a solução consensual dos conflitos" e, a seguir, no $\S 3^{\circ}$, prevê que "a conciliação, a mediação e outros métodos de solução consensual de conflitos deverão ser estimulados por juízes, advogados, defensores públicos e membros do Ministério Público, inclusive no curso do processo judicial".

RC: 87863

Disponível em: https://www.nucleodoconhecimento.com.br/sem-categoria/conciliacao-e$\underline{\text { mediacao }}$ 
Em sequência, vários outros atos normativos foram repensados e em relação à parte extrajudicial existiu também um ato que tramitou no congresso de 2015 a 2018 que foi a PEC 108 de 2015 que buscava o tratamento dos meios extrajudiciais de resolução de conflitos como um direito fundamental, ou seja, a par da solução de conflitos no âmbito do poder judiciário, apesar dessa PEC não tenha sido implementada, sabe-se que o Brasil, portanto, está cada vez mais tentando a implementação dessas modalidades de resolução de conflitos no âmbito extrajudicial e talvez esse âmbito extrajudicial seja muito mais importante de ser implementado do que o judicial.

Salienta-se que a PEC 108/2015, retro mencionada, foi um documento importante, já que tentou acrescentar 0 inciso LXXIX ao art. $5^{\circ}$ da Constituição Federal, para estabelecer o emprego de meios extrajudiciais de solução de conflitos como um direito fundamental e incluir entre os direitos e deveres individuais e coletivos o estímulo pelo Estado à adoção de métodos extrajudiciais de solução de conflitos.

Acontece que analisando o provimento $N^{\circ} 67 / 2018$ verificou-se que existem algumas dúvidas para que aconteça o efetivo exercício do serviço das serventias extrajudiciais, geralmente em relação à logística de implementação e quanto à padronização das atividades a serem realizadas.

Assim, tendo em vista, a necessidade de estudo apresentada pela disciplina de mestrado, buscou-se, primeiramente, abordar sobre a conciliação e mediação como métodos de resolução de conflito para a posteriori adentrar no estudo detalhado do Provimento $N^{\circ} 67 / 2018$.

Da análise do provimento em questão e das atuais práticas cartorárias espalhadas pelo Brasil encontrou-se, alguns pontos controvertidos, e para delimitar o estudo foram escolhidos alguns deles, quais sejam, a falta de uma política institucional uniforme, a questão de atuação e capacitação do conciliador/mediador serventuário, o rompimento do princípio de confidencialidade, a representação por procuração, a impossibilidade de requerimento de resolução de conflitos familiares, os reflexos da

RC: 87863

Disponível em: https://www.nucleodoconhecimento.com.br/sem-categoria/conciliacao-emediacao 
devida homologação judicial dos acordos extrajudiciais, a necessidade de previsão legal para cobrança de valores e a falta de unificação de remuneração.

Com essa abordagem buscou-se trazer um viés criativo, ao analisar o tema sob o enfoque das possíveis consequências provocadas pela implementação do provimento $n^{\circ} 67 / 2018$ no Brasil da forma que veio delimitado.

Para fazer esse tipo de recorte faz-se necessário a explanação dos métodos adequados em resolução de conflitos consubstanciando a base para apresentação posterior do provimento $n^{\circ} 67 / 2018$ e das controvérsias geradas pela sua aplicação.

\section{MÉTODOS ADEQUADOS EM RESOLUÇÃO DE CONFLITOS}

Reconhece-se que o caminho em busca da superação da formação tradicional vem sendo trilhado e que a passagem de um ensino modular e normativo para um modelo onde não há instrumentos e intervenções pré-definidas, necessitará não só de mudanças de atitudes, mas, também, de mudanças institucionais e estruturais.

Importante salientar que as emergências da nova era não oportunizam mais espaços para longos litígios. Segundo Feigelson (2017, p.21), "no âmbito das grandes corporações, o sinal dos novos tempos está na privatização da resolução dos conflitos que se dá por meio da arbitragem". Da mesma forma, é crescente a adoção e da mediação e da conciliação, já que no campo da advocacia 2.0, o papel de "negociador" será muito mais prestigiado do que o "litigante".

Coura e Pimentel (2017, p. 44), escrevendo sobre as 23 carreiras possíveis para aquele que se forma em Direito cita a de mediador, ou seja,

a daquele que ajuda as partes que já se conhecem a restabelecer um canal de comunicação, onde o acordo não é uma consequência necessária e para que aconteça sua atuação é necessário que o profissional faça um curso de capacitação de mediadores oferecido pelos tribunais ou câmaras de mediação.

RC: 87863

Disponível em: https://www.nucleodoconhecimento.com.br/sem-categoria/conciliacao-e$\underline{\text { mediacao }}$ 
Os cartórios não poderiam ficar à margem da possibilidade de participar dessa mudança de paradigma cultural das sentenças, já que, ajudariam em muito com a redução de atos judicializados, já que é também sabido que existem, atualmente no Brasil, cerca de 13.550 cartórios distribuídos por nosso território constituindo uma rede de interação com uma importância social fundamental.

O dado supracitado poderá ser conferido no Cadastro Nacional de Serventias Públicas e Privadas do Brasil apresentado no Portal do Ministério da Justiça[3].

Assim, amparados pelo Provimento № 67/2018 do CNJ, e pela Resolução 125/2015 do CNJ e pela Lei de Mediação, Lei № 13.140/2015, os cartórios brasileiros começaram a saga de implementação dessa política nacional de resolução de conflitos.

Dentre os métodos adequados autorizados para funcionarem no âmbito cartorial são: a conciliação e a mediação, onde tanto o primeiro quanto o segundo são considerados mecanismos alternativos ou adequados de resolução de conflitos entre duas ou mais pessoas que oportunizam às partes envolvidas, antes de litigar na via judicial, um caminho mais rápido e menos moroso.

\subsection{CONCILIAÇÃO}

A adoção de técnicas destinadas à solução de conflitos mediante correção de percepções unilaterais e desproporcionais das partes dá-se através da conciliação, cujo objetivo principal é expandir a comunicação entre as partes, de forma a permitir uma troca positiva de opiniões e discussões entre elas, que tornem possível o acordo, sendo que a própria habilidade das partes, envolvidas neste processo, são de criar métodos cooperativos e eficazes para solução dos conflitos.

Considerando a questão comparativa entre a conciliação e a mediação podemos dizer que o primeiro mecanismo tem como características principais a utilização de técnicas

RC: 87863

Disponível em: https://www.nucleodoconhecimento.com.br/sem-categoria/conciliacao-e$\underline{\text { mediacao }}$ 
e ferramentas para resolução de conflitos de pequena complexidade, sem grande interesse em manter o vínculo entre as partes envolvidas e com a permissão de movimentos sugestivos do conciliador facilitador.

Enquanto a mediação, segundo método apresentado, abarca as questões de maior complexidade como será explicitado a seguir.

\subsection{MEDIAÇÃO}

Com o objetivo similar da conciliação surge como mecanismo permitido o da mediação de conflitos com o diferencial de que sua utilização é recomendada para conflitos de médio e/ou grande complexidade, com interesse na manutenção dos vínculos entre os interessados e com impedimento quanto a utilização de técnicas/ferramentas sugestivas pelos profissionais devidamente capacitados, já que o mediador será apenas o facilitador da retomada da comunicação desvencilhada e não poderá influenciar, seja positiva ou negativamente, nas decisões negociáveis.

Interessante citar que a mediação apesar de recentemente aplicada no Brasil não pode ser considerado como um novo mecanismo alternativo ou adequado de resolução de conflitos, já que conforme, Nader (1988, p. 269), "as civilizações antigas já utilizavam a mediação".

O histórico do emprego pretérito da mediação como mecanismo resolutivo pode ser comprovado por referências retiradas de ensaios filosóficos chineses, como por exemplo, os da época de Confúcio (551-479 a. C.), que retratam, mesmo antes de Cristo, essa forma de resolução de conflitos levando em conta a justaposição de questões puramente legais por meio da principiologia moral, onde as partes envolvidas aparecem, de forma concreta, beneficiadas e contentadas, com a construção resolutiva através de manifesto acordo e entrosamento entre elas (SERPA, 1999).

RC: 87863

Disponível em: https://www.nucleodoconhecimento.com.br/sem-categoria/conciliacao-e$\underline{\text { mediacao }}$ 
A ideia referenciada anteriormente sobre o prelúdio da utilização da mediação com base na filosofia de Confúcio (Kung-fu-tzu) pode ser constatada nos estudos de Maria de Nazareth Serpa (1999 apud MOLOGNI, 2003; MORAES, 2012; COELHO e BONATO, 2018) que afirma que:

Os chineses, na Antiguidade, influenciados pelas ideias do filósofo Confúcio, já praticavam a mediação como principal meio de solucionar contendas. Confúcio acreditava ser possível construir-se um paraíso na terra, desde que os homens pudessem se entender e resolver pacificamente seus problemas. Para ele existia uma harmonia natural nas questões humanas que não deveria ser desfeita por procedimentos adversariais ou com ajuda unilateral. Seu pensamento estabelecia que a melhor e mais justa maneira de consolidar essa paz seria através da persuasão moral e acordos e nunca através da coerção ou mediante qualquer tipo de poder.

Vejamos também a posição de Maria Bernadete Miranda (2012, p. 3), onde para ela Confúcio pregava a utilização da mediação como necessária para que ocorresse uma ordem social harmônica que deveria ser regida diretamente pelas partes, incluindo as pessoas com poder de governar, através da proposta de um código de comportamento afável, sendo assim, essas pessoas agiriam com consenso e civilidade buscando o mecanismo resolutivo em si para gerir os conflitos apresentados. Em relação a esse aspecto: "A mediação iniciou-se na China, graças à essência do pensamento de Confúcio pela busca da harmonia através do equilíbrio do mundo e da felicidade dos homens. Para os chineses o equilíbrio das relações sociais estava em primeiro plano)".

Em continuidade busca-se uma definição generalizada sobre a mediação e, nesse momento, foi prudente utilizar as considerações trazidas por Moreira (2012, p. 274) que considera a mediação como uma proposta de retomada da comunicação entre os envolvidos através da autonomia de vontades com a participação facilitadora do mediador.

Sendo assim, na mediação, as partes envolvidas, com auxílio do mediador e não por imposição deste, construirão alternativas resolutivas com o entendimento sobre a

RC: 87863

Disponível em: https://www.nucleodoconhecimento.com.br/sem-categoria/conciliacao-e$\underline{\text { mediacao }}$ 
autorresponsabilização de cada um para que haja a (des) escalada conflitiva e estabilização da paz social.

A mediação pode ter por objeto, tanto direitos disponíveis quanto indisponíveis, transigíveis. Nesse último caso, o acordo somente terá validade depois de ouvido o Ministério Público e da homologação judicial - é exemplo o acordo que envolve alimentos, que têm conteúdo patrimonial. Direitos patrimoniais, aliás, de acordo com Zenker e Silva (2018, p. 88)

são o objeto central da mediação, já que é mais comum estarmos diante de situações que envolvam valor econômico. Destarte, direitos obrigacionais, creditícios, pessoais e reais, podem ser objeto de mediação, ao passo que os direitos extrapatrimoniais têm alcance reduzido quando se trata de mediação (direito à imagem, por exemplo).

\section{PROVIMENTO 67 DE 26 DE MARÇO DE 2018 DO CONSELHO NACIONAL DE JUSTIÇA (CNJ)}

O provimento 67/2018 surgiu a partir de duas dúvidas que chegaram ao $\mathrm{CNJ}$ : 1) consulta gerada em 2016 (Processo no 0003416-44.2016.2.00.0000): "se os notários e os registradores poderiam fazer a conciliação e a mediação no âmbito judicial e 2) se os cartórios efetivamente poderiam oferecer os serviços de conciliação e mediação".

De acordo com Trícia Cabral (2018, p. 5):

$\mathrm{O} \mathrm{CNJ}$ em relação à primeira consulta, ou seja, se os notários e os registradores poderiam atuar como conciliadores e mediadores perante o tribunal de justiça ponderou que não haveria qualquer óbice. Mas, em relação aos cartórios oferecerem os serviços de conciliação e mediação dependeria de uma outra regulamentação padronizando o procedimento nos cartórios no Brasil inteiro e essa regulamentação foi justamente o provimento $\mathrm{N}^{\circ} 67 / 2018$ que surgiu para trazer uma certa segurança jurídica principalmente para os consumidores desse tipo de serviço.

RC: 87863

Disponível em: https://www.nucleodoconhecimento.com.br/sem-categoria/conciliacao-e$\underline{\text { mediacao }}$ 
Então, esse provimento com 42 artigos na verdade tenta conjugar o que estava estabelecido na política nacional (Resolução 125/2010) com o que estava estabelecido na Lei de Mediação que em seu artigo 42 já trazia possibilidade de as serventias extrajudiciais oferecerem os serviços de mediação e conciliação.

E para corroborar com a necessidade da oferta dos mecanismos extrajudiciais no cartório, de antemão Pedrosa (2018) enfatiza a confiança e capilaridade das serventias extrajudiciais para o sucesso da aplicabilidade da conciliação/mediação como métodos eficazes para a melhoria social. Vejamos:

O amadurecimento responsável da sociedade é um objetivo emergencial num país que clama por melhorias, e nada melhor que contar com a força integral dos Cartórios para promover com sucesso a conciliação e mediação. Vale lembrar, em arremate, que o Provimento do CNJ reconheceu, ainda que implicitamente, duas premissas importantes que trago à baila novamente: CONFIANÇA nos serviços prestados pelos Cartórios do Brasil e CAPILARIDADE eficiente das Serventias, pois presentes em quase todo o País (grifamos).

Essa regulamentação, de modo geral, foi muito bem-vinda e bem-produzida, mas, como qualquer ato legislativo sempre ocorre algumas dúvidas e expectativas de melhoramento e na prática, também, acontece alguns questionamentos quanto a viabilidade e logística da implementação desses serviços.

Nesse estudo discorre-se sobre alguns pontos controversos para provocação de melhorias não só para esclarecer como também para amadurecimento do que está previsto no provimento $\mathrm{N}^{\circ} 67 / 2018$ para que haja uma padronização procedimental em todo território nacional de uma forma transparente.

\section{QUESTÕES CONTROVERTIDAS}

Apesar do exercício da atividade notarial e registral estar presente em quase todos os municípios brasileiros, com estrutura, conhecimento jurídico, confiabilidade e fé pública e devido a isso ser uma boa opção para a resolução de conflitos de uma forma

RC: 87863

Disponível em: https://www.nucleodoconhecimento.com.br/sem-categoria/conciliacao-emediacao 
mais rápida, ao debruçar-se no provimento regulatório percebe-se que existem alguns pontos controvertidos que serão a partir do momento discutidos.

\subsection{FORMA DE ATUAÇÃO E CAPACITAÇÃO DO SERVENTUÁRIO COMO CONCILIADOR/MEDIADOR}

Com o advento da Lei oㅡ 13.140/2015 surgiu a possibilidade de a atividade notarial colaborar ainda mais para o cenário jurídico, ao permitir a institucionalização, no âmbito de sua competência, das atividades de conciliação e de mediação. Parece-nos que a atividade notarial poderá ser mais bem utilizada do que já é, ampliando sua capacidade de intermediação entre as partes na direção de prevenir a violação de direitos pela promoção conservatória do diálogo. Observa-se que, para o exercício da mediação, o notário necessariamente precisaria comprovar ter realizado curso credenciado de mediação, de forma a estar apto para o exercício de tal função, nos termos da Lei 13.140, art. 9o (BRASIL, 2015).

Sabe-se que o tabelião de notas não pode praticar "atos de seu ofício" fora do município para o qual receber a delegação, como isso pode afetar sua atuação como conciliador/mediador?

Podemos responder ao questionamento anterior através da consideração de que existe possibilidade de que o tabelião (notário) atue como mediador aludindo em consideração as premissas da legislação afeta a atividade notarial no Brasil estabelecidas na Lei 8.935/1994. Inicialmente, temos que o notário não detém competência territorial para atuar em outros municípios que não o de sua Comarca. Conforme preceitua o art. 9ํำ da Lei 8.935/1994, o tabelião de notas não pode praticar "atos de seu ofício" fora do município para o qual recebeu a delegação. Logo, cingese a controvérsia no sentido de saber se a mediação seria ou não ato de ofício do tabelião (BRASIL, 1994). 
Se uma das funções do notário é justamente atuar como assessor jurídico e imparcial, emprestando fé pública aos negócios jurídicos e impingindo em seus atos a segurança jurídica necessária, parece-nos que a mediação se enquadraria dentre as atribuições ofertadas ao tabelião.

Retornando o foco para o primeiro questionamento deve-se atentar para o fato de que a atuação notarial deve obedecer à territorialidade imposta pela legislação que rege a matéria. Noutras palavras, o Tabelião pode atuar como mediador nas matérias que Ihe são afetas (competência material), mas não pode extrapolar os limites de sua comarca (competência territorial).

Ademais, a seara de atuação do notário é a preventiva. Uma vez designado como mediador, através de portaria, o tabelião deve ser sujeito imparcial, que busca aproximar e aconselhar as partes, formalizar juridicamente suas vontades e velar pela validade e eficácia de modo a evitar que o acordo seja fonte de conflitos futuros. No exercício da profilaxia notarial, a mediação extrajudicial poderá diminuir a lide, entendida essa como um "conflito de interesses degenerado pela pretensão de uma das partes e pela resistência da outra" (CÂMARA, 2011, p. 76).

Avançando para o segundo questionamento relativo à capacitação do tabelião para sua atuação como conciliador e/ou mediador, pergunta-se se está deverá ser nos moldes do CNJ custeada pelos cartórios, com relação específica pelos facilitadores ou não?

Respondendo a esse questionamento podemos dispor de algumas das conclusões trazidas em inúmeros escritos elaborados por Cabral (2018) e em outros tantos por Hill (2018) referenciando os ensinamentos trazidos no artigo $6^{\circ}$ do referido provimento $N^{\circ} 67 / 2018$. 
Observa-se nas palavras de Trícia Cabral (2018) a satisfação quanto aos mandamentos trazidos no corpo do artigo 6ㅇ quanto ao currículo expresso no Anexo I da Resolução 125 de 2010 (Emenda 2/2016), vejamos:

quanto ao requisito obrigatório referente a formação/capacitação dos facilitadores, tabeliões ou notários. Precisando, necessariamente, observar a previsão de seu $\S^{2}{ }^{\circ}$ quanto a obrigatoriedade da realização de curso de aperfeiçoamento no intervalo de 2 em 2 anos com custos suportados pelos órgãos cartorários, em observância ao $\$ 1^{\circ}$ (grifamos).

Outra informação trazida por Cabral (2018), é a de que:

devemos considerar como resposta complementar desse questionamento é a "de que será o Núcleo Permanente de Mediadores e Conciliadores (NUPEMEC) é o principal responsável pelo cadastramento dos profissionais habilitados, bem como pela colheita e publicação dos dados referenciais de qualidade e quantidade ligados a forma de atuação dos tabeliões e notários que praticam a conciliação/mediação, expressa no artigo $5^{\circ}$, parágrafos $1^{\circ}$ e $2^{\circ}$ do provimento em estudo (grifamos).

Conforme estipulado no provimento, o rol de conciliadores e mediadores, por listagem geral, com presença de todos as pessoas capacitadas ou em rol específico de cada região, ou seja, para cada cartório independentemente, será aperfeiçoado por notários, tabeliões, escreventes (limitado até cinco participantes) ou terceiros recomendados pelo órgão cartorário, que atuam nomeadamente com serviços notarias e de registro, onde tais profissionais são de livre escolha pelas partes.

Outro questionamento interessante é o relacionado a dinâmica de utilização de profissionais cadastrados em outras serventias ou no próprio $\mathrm{CNJ}$, em obediência aos mandamentos explícitos na portaria de que cada cartório deverá ter cinco pessoas capacitadas e cadastradas como facilitadores de resolução de conflitos.

Sendo assim, poderão os órgãos cartorários, quando for nulo ou mesmo deficitário o número de profissionais habilitados em sua instância, recorrer ao rol de cadastros de outras serventias ou mesmo do próprio CNJ?

RC: 87863

Disponível em: https://www.nucleodoconhecimento.com.br/sem-categoria/conciliacao-e$\underline{\text { mediacao }}$ 
$\mathrm{Na}$ leitura da portaria entende-se que, independentemente de quem estará financiando o procedimento, a atuação de conciliadores/mediadores nos cartórios não está subordinada aqueles pertencentes ao quadro interno do órgão cartorial, podendo, os cartórios, buscar socorro nas listas públicas existentes na Corregedoria ou no NUPEMEC quando necessário.

Para um cartório grande cinco serventuários é muito pouco, devido a quantidade de demandas e para um cartório pequeno, cinco serventuários é, muito dispendioso, já que tanto o investimento financeiro dos cartórios pode onerar muito o dono do cartório e os funcionários (os poucos que estão habilitados) não terão como ao mesmo tempo fazer seu serviço ordinário e as conciliações/mediações.

Para os cartórios pequenos, uma alternativa seria que pelo menos existisse a figura do registrador capacitado para que ele tenha a autorização do NUPEMEC e da Corregedoria, pela questão da fiscalização e da necessidade da triagem prévia, da verificação de direito disponível ou indisponível.

Assim, uma pessoa, ou seja, o próprio tabelião ou seu substituto teria que ser alguém qualificado e autorizado.

Portanto, nesse quesito, nota-se que são questões de ordem prática, onde existiria algumas propostas de adequação, uma delas é a qualificação de pelo menos uma pessoa e a outra seria a que a própria parte poderia levar seu próprio mediador (mediador ad hoc) com a exigência da assinatura de um termo de responsabilidade.

Outra hipótese levantada após a leitura da portaria é quanto ao tipo de espécie da conciliação/mediação aplicada nos cartórios. A conciliação/mediação cartorária funciona somente através do engessamento judicial ou poderá ser utilizada com os moldes da forma extrajudicial?

Percebe-se que mesmo que a previsão trazida pela portaria seja de que a atuação do serventuário (notário ou tabelião) como conciliador/mediador deverá acontecer de $\mathrm{RC}: 87863$

Disponível em: https://www.nucleodoconhecimento.com.br/sem-categoria/conciliacao-e$\underline{\text { mediacao }}$ 
uma forma extrajudicial, na prática acontece de uma forma híbrida, ou seja, com peculiaridades tanto da mediação judicial quanto da extrajudicial.

Corroborando com a ideia supracitada podemos citar Hill (2018, p. 5), que afirma que "a mediação realizada pelos serventuários nos cartórios enquadra-se em uma forma híbrida de atuação, misturando as formas judiciais com as extrajudiciais".

Portanto, mesmo que apareça expresso no artigo 36 do Provimento $N^{\circ} 67 / 2018$ que a forma de mediação adotada seria a extrajudicial, já que ainda que o cartório extrajudicial precise se credenciar formalmente como Cejusc, o fato é que a mediação se dará nas dependências do cartório e não em uma sala do tribunal.

Ainda pelas conclusões de Hill $(2018$, p. 7) tem-se a afirmação de que:

O Provimento ำ 67/2018 do CNJ parece indicar que a mediação conduzida pelas serventias extrajudiciais, de fato, se submete a um regime híbrido, um tertium genus, já que apesar de aproxima-se do regime da mediação judicial não coincide perfeitamente com o modelo de mediação judicial, pois, constata-se que a mediação em questão se aproxima em boa medida do modelo extrajudicial, visto que o procedimento se desenvolve nas dependências do cartório extrajudicial, portanto, fora das instalações físicas do fórum, o que auxilia a desvincular a mediação da solução adjudicada estatal e a desvanecer o temor reverencial que o Estado-juiz faz emergir. Ainda que o cartório extrajudicial precise se credenciar formalmente como Cejusc, o fato é que a mediação se dará nas dependências do cartório e não em uma sala do tribunal.

Ademais,

fazendo a leitura atenta do artigo $4^{\circ}$ do provimento № $67 / 2018$ do CNJ percebe-se que independente da forma ser judicial, extrajudicial ou híbrida, como suprimento de requisito legal, a conciliação/mediação aplicada no ambiente cartorial será sempre de responsabilidade de suas serventias através do princípio da autonomia de gestão e de supervisão cabível em cada órgão (CABRAL, 2018).

RC: 87863

Disponível em: https://www.nucleodoconhecimento.com.br/sem-categoria/conciliacao-e$\underline{\text { mediacao }}$ 
Em complementação aos questionamentos anteriores podemos reforçar a competência das serventias extrajudiciais para a realização de conciliação/mediação com os argumentos trazidos por Alberto Gentil de Almeida Pedrosa (2018), vejamos:

Entendo que a conciliação/ mediação no extrajudicial deverá ser realizada por todos os notários e registradores, de maneira ampla e irrestrita, desde que preenchidos dois requisitos: 1) habilitação da serventia junto ao NUPEMEC, seguida da capacitação dos Titulares e escreventes (até o número máximo de 5 escreventes por Cartório) nos termos do Provimento no 67/2018; 2) livre escolha das partes conforme dispõe o art. 168 do CPC e a parte final do art. 3ำ do Prov. ํo 67/2018. Deve ficar claro que não é do espirito da norma processual civil comum, tampouco poderia ser do Provimento do CNJ, limitar a conciliação e a mediação de qualquer modo, tampouco fracionar a sua competência - mostrando-se inócuo o disposto no art. 13 da regra administrativa (quanto a observância da formulação do requerimento de conciliação e mediação em observância as respectivas competências do art. 42 da Lei $\left.n^{\circ} 13.140 / 2015\right)$ quando não existe qualquer previsão legal de apuração de atribuição, tampouco disposição sobre "possível conflito de atribuição" no caso de dois registradores ou notários entenderem que ambos detém "melhor competência (grifamos).

\subsection{INEXISTÊNCIA DE UMA POLÍTICA INSTITUCIONAL UNIFORME}

A pergunta base para o desenvolvimento desse tema é a implementação dos mecanismos alternativos de resolução de conflitos pelas serventias extrajudiciais.

A inserção da conciliação/mediação no âmbito dos cartórios brasileiros, sem padronização legal e de certa forma desordenada, prejudica a implementação de uma política institucional uniforme?

A resposta para essa pergunta é que como o próprio provimento $N^{\circ} 67 / 2018$ delega que as corregedorias estaduais e o Distrito Federal possam particularizar, através de seus próprios provimentos, a atividade em razão da necessidade local de cada cidade/município. 
Ademais, a aplicação do provimento não será automática. Trícia Cabral (2018) afirma que:

Nos termos do art. $4^{\circ}$, o processo de autorização dos serviços notariais e de registros para a realização de conciliação e de mediação deverá ser regulamentado pelos NUPEMECs e pelas Corregedorias-gerais de Justiça (CGJ) dos estados e do Distrito Federal. O ideal, para se manter uma padronização nacional, seria que todos os tribunais regulassem de forma semelhante a matéria, ainda que observadas as peculiaridades de cada estado ou região, assegurando a implementação de uma política institucional uniforme.

A regulamentação pelas corregedorias e pelos NUPEMECs prevista no artigo $4^{\circ}$ do Provimento 67/2018 traz que também outro questionamento implícito: A regulamentação sobre o procedimento terá autorização para funcionamento dos cartórios conjuntamente pela corregedoria e pelos NUPEMECs ou somente pela Corregedoria-geral?

Tanto os NUPEMECS quanto as Corregedorias-gerais possuem sob sua responsabilidade a liberação para funcionamento de conciliação e mediação no âmbito das serventias cartorárias. Vejamos a posição de Trícia Cabral (2018) em relação a esse aspecto:

O processo de autorização dos serviços notariais e de registro para a realização de conciliação e de mediação deverá ser regulamentado pelos NUPEMECs e pelas Corregedorias-gerais de justiça (CGJ) dos Estados e do Distrito Federal e dos Territórios e os serviços notariais e de registro poderão solicitar autorização específica para que o serviço seja prestado, sob supervisão do delegatário, por no máximo cinco escreventes habilitados.

Em complementação as ideias apresentadas por Trícia Cabral (2018), vejamos as ideias de Alberto Gentil de Almeida Pedroso ao afirmar que:

O Provimento introduz um sistema de fiscalização combinada entre o NUPEMEC e a CGJ - fixando pontos de atuação conjunta e temas de competência individual. O NUPEMEC e a CGJ regularão o processo de autorização dos serviços notariais e de registro para realização da conciliação e mediação. De igual modo, ambos fiscalizarão os

RC: 87863

Disponível em: https://www.nucleodoconhecimento.com.br/sem-categoria/conciliacao-e$\underline{\text { mediacao }}$ 
procedimentos de conciliação e mediação. Todavia, entendo que alguns cenários se mostram bem definidos - NUPEMEC: manterá cadastro de conciliadores e mediadores habilitados, do qual deverão constar dados relevantes de atuação, tais como o número de causas de que participou, o sucesso ou insucesso da atividade, a matéria sobre a qual versou a controvérsia, além de outras informações que julgar relevantes; Os dados colhidos serão classificados sistematicamente pelo NUPEMEC, que os publicará, ao menos anualmente, para conhecimento da população e para fins estatísticos e de avaliação da conciliação e da mediação pelos serviços notariais e de registro e de seus conciliadores e mediadores; controle quanto a capacitação dos conciliadores e mediadores em cursos oferecidos pelas escolas judiciais ou por instituições formadoras de mediadores judiciais, nos termos do art. 11 da Lei n. 13.140/2015, regulamentada pela Resolução ENFAM n. 6 de 21 de novembro de 2016. - CGJ: caberá ao Juiz Corregedor Permanente fiscalizar o livro de protocolo especifico para o recebimento de pedidos de conciliação e mediação nas serventias optantes pela prestação do serviço; caberá ao Juiz Corregedor Permanente fiscalizar também o livro de conciliação e de mediação, cuja abertura atenderá às normas estabelecidas pelas Corregedorias Gerais de Justiça dos Estados e do Distrito Federal e dos Territórios; por fim, é de competência da CGJ (assim como do Juiz Corregedor Permanente) a fiscalização do Titular da Serventia quanto à regularidade, eficiência e celeridade da prestação do novo serviço.

\subsection{ROMPIMENTO DO PRINCÍPIO DE CONFIDENCIALIDADE}

A confidencialidade é um princípio basilar, fundamental e necessário para a efetivação ética e correta dos processos de conciliação e mediação, tanto judicial quanto extrajudicialmente. E não deveria ser diferente quanto a utilização desses mecanismos resolutivos de conflitos nas vias cartorárias.

Acontece que diferentemente do que acontece nas outras vias extrajudiciais de resolução de conflitos, nas serventias extrajudiciais e nos cartórios, como procedimento padronizado, é necessário o registro em livros e notas. O provimento № $67 / 2018$ do CNJ, como medida de exceção, trouxe artigos expressos correlacionados a esse fato de rompimento, mesmo que de forma relativa, do princípio de confidencialidade.

Vejamos a posição de Trícia Cabral (2018) em relação a esse aspecto:

RC: 87863

Disponível em: https://www.nucleodoconhecimento.com.br/sem-categoria/conciliacao-emediacao 
O provimento diz que livros vão registrar a mediação e que ficarão sob guarda dos cartórios. Sendo assim, para a prestação dos serviços de conciliação e mediação pelos serviços notariais e de registro, será necessária a criação de três livros: a) livro de protocolo específico para requerimentos de conciliação e de mediação; b) livro de conciliação e de mediação contendo os termos de audiência de conciliação ou de mediação; c) livro de conciliação e de mediação para a lavratura de audiências por meio eletrônico (artigos 26 a 35) (grifamos).

A polêmica nesse caso é quanto ao ferimento ao princípio da confidencialidade, já que tudo declarado durante o curso da mediação é confidencial. A obrigação de confidencialidade estende-se a todos os participantes (o mediador do sigilo profissional e a confidencialidade das partes, de acordo com o princípio da boa-fé) sendo fundamentais para preservar o espaço da mediação como espaço cooperativo, promovendo a geração de confiança e evitar a instrumentalização do processo por uma ou ambas as partes.

Outra dimensão relevante de confidencialidade refere-se à informação que uma das partes faz ao mediador nas entrevistas individuais, informação que não pode ser divulgada às outras partes sem autorização.

O sigilo das questões trazidas pelas partes otimiza a confiança entre todos os envolvidos e permeia o princípio da cooperação entre as partes promovendo, sem dúvidas, a abertura para resoluções exitosas. Nesse ínterim é necessário a observação trazida por Trícia Cabral em seus artigos:

Também denominado de princípio do sigilo, a exigência de confidencialidade é essencial para a garantia de que as sessões de mediação ou conciliação possam ter maior chance de sucesso. Isso porque, garantindo que as informações utilizadas nessas sessões não possam ser utilizadas em processo judicial e em outros, isso permite que as partes se sintam mais à vontade para estabelecer um diálogo aberto.

Do contrário, sempre haveria o receio de uma determinada informação desfavorável, a exemplo de uma parte que aborda o problema envolvido, reconhecendo sua culpa poder ser utilizada no litígio judicial.

RC: 87863

Disponível em: https://www.nucleodoconhecimento.com.br/sem-categoria/conciliacao-e$\underline{\text { mediacao }}$ 
A principal função da confidencialidade é a de proteger os seus participantes no caso de ausência de acordo, impedindo que possam ser utilizadas em seu desfavor no processo judicial. Em decorrência do dever de confidencialidade, o facilitador não será obrigado a depor de fatos que envolvam o exercício de sua atividade, aplicando-se, no caso, o art. 448, II, do CPC/2015. Trata-se de um direito e de um dever essencial ao exercício de sua profissão.

Sendo assim, o registro dos termos contendo os termos da audiência de conciliação ou mediação podem vir a ferir a essência do princípio da confidencialidade, pode até esvaziá-lo, já que, e por serem livros públicos poderão ser manuseados por qualquer pessoa desmontando teses sigilosas e acordos confidenciais.

\subsection{IMPOSSIBILIDADE DE REQUERIMENTO DE RESOLUÇÃO DE CONFLITOS FAMILIARES}

Diante da abertura para a realização, pelas serventias extrajudiciais, de conciliação e de mediação envolvendo direitos indisponíveis, mas transacionáveis, existe a possibilidade de o requerimento ter como objeto conflitos familiares, envolvendo menores, ainda que devidamente representados ou assistidos?

A resposta é negativa. Vejamos o posicionamento de Trícia Cabral (2018): "Isso porque o Estado, no intuito de preservar relações familiares e de proteger crianças, adolescentes e idosos, entendeu necessário submeter ao Poder Judiciário, a resolução de conflitos que envolvam os referidos temas (grifamos)".

Mais a mais, reforçando a impossibilidade de requerimento de resolução de conflitos familiares envolvimento menores e estendendo-se, no nosso ponto de vista, para pessoas com debilidades mentais, idosos, entre outros, Cabral $(2018$, p. 4) reforça seu argumento, vejamos:

O artigo 12 do provimento dispõe que poderão ser objeto de conciliação e de mediação direitos disponíveis ou os indisponíveis que admitam transação. Por sua vez, o objeto da conciliação e da mediação também poderá versar sobre todo o conflito ou parte dele. Assim, na autocomposição envolvendo direitos disponíveis não se

RC: 87863

Disponível em: https://www.nucleodoconhecimento.com.br/sem-categoria/conciliacao-e$\underline{\text { mediacao }}$ 
exigirá a homologação judicial, cabendo às partes optar por transformar o título executivo extrajudicial em judicial, nos termos do artigo 515, III, do CPC. Já o acordo envolvendo direitos indisponíveis, mas transigíveis, deverá ser obrigatoriamente homologado, cabendo ao cartório providenciar a remessa ao juízo competente e, após a homologação, entregar o termo homologado às partes (artigo 12, parágrafos $1^{\circ}$ e $\left.2^{\circ}\right)$.

Diante dessa abertura para a realização, pelas serventias extrajudiciais, de conciliação e de mediação envolvendo direitos indisponíveis, mas transacionáveis, questiona-se sobre a possibilidade de o requerimento ter como objeto conflitos familiares, envolvendo menores, ainda que devidamente representados ou assistidos.

A resposta é negativa. Isso porque o Estado, no intuito de preservar relações familiares e de proteger crianças, adolescentes e idosos, entendeu necessário submeter, ao Poder Judiciário, a resolução de conflitos que envolvam os referidos temas. Dessa forma, não se mostra viável, na atual conjuntura legislativa, a realização de conciliação ou mediação no âmbito dos serviços notariais e de registro que tenham por objeto matérias que por determinação legal dependam de chancela judicial, salvo se houver alteração legislativa.

Acontece que a retirada dessa possibilidade dos cartórios, ou seja, a possibilidade de resolução de questões que envolvem direitos indisponíveis mais transigíveis, como é o caso das questões familiares, promove o claro esvaziamento deles em contraposição a ideia de ampliação das redes de trabalho desses ofícios.

Ademais, outro questionamento é referente a impossibilidade de menor fazer o requerimento referente a utilização dos mecanismos alternativos e extrajudiciais pelos cartórios, já que não possui autonomia de vontades, pois necessita do instituto da representação. Ademais, a resolução dos conflitos os envolvendo necessitaria da proteção do Ministério Público e da homologação judicial. 


\subsection{REFLEXOS DA DEVIDA HOMOLOGAÇÃO JUDICIAL DOS ACORDOS EXTRAJUDICIAIS}

Caso as partes tenham chegado a um consenso sobre determinada discussão na conciliação/mediação nas serventias notariais e de registros, e seja de suas vontades conferirem o status de título executivo judicial aos termos do aludido acordo, seria possível pleitear sua homologação judicial?

No caso de conciliação/mediação ocorrida nas serventias extrajudiciais, de acordo com Cabral (2018): “(...) se ainda assim as partes e/ou seus advogados acharem necessário, o termo de acordo poderá ser levado à homologação junto aos CEJUSC's onde se encontram cadastradas ou na Justiça Expressa".

Assim, é possível conseguir com a conciliação/mediação, a certeza e a segurança, de acordo com Cabral (2018) "gerada pelo Poder Judiciário, mas com muito mais celeridade, eficiência, e ainda, menores custas e desgastes dos litígios morosos".

A controvérsia surge quando os juízes não quiserem homologar os acordos gerados nos cartórios, esvaziando, sobremaneira, o princípio da autonomia de vontades, princípio esse basilar dos métodos adequados em resolução de conflitos.

\subsection{INEXISTÊNCIA DE UNIFICAÇÃO DE REMUNERAÇÃO}

No âmbito das serventias extrajudiciais, a questão da remuneração dos conciliadores/mediadores é amplamente discutida, mas, ainda distante de ser contornada e de acordo com Cabral (2018), necessita da observação das diretrizes trazidas pela Lei 10.169/2000, bem como de uma regulamentação legislativa específica. Percorramos:

Contudo, o caput do artigo 36 do Provimento 67/2018 determina igualmente os emolumentos para conciliações e mediações, fixando o menor valor cobrado na lavratura de escritura pública sem valor econômico. E ainda determina que, na hipótese de o arquivamento do

RC: 87863

Disponível em: https://www.nucleodoconhecimento.com.br/sem-categoria/conciliacao-e$\underline{\text { mediacao }}$ 
requerimento ocorrer antes da sessão de conciliação ou mediação, $75 \%$ (setenta e cinco por cento) do valor recebido deverá ser restituído.

Em continuidade à discussão sobre a inexistência de uma unificação remuneratória para os conciliadores/mediadores cartorários, Cabral (2018, p. 2) afirma que:

de acordo com o artigo 16 do Provimento 67/2018, no ato do requerimento, o requerente pagará emolumentos referentes a uma sessão de mediação de até 60 minutos. Enquanto não regulamentados os emolumentos no âmbito dos estados e do Distrito Federal, aplicar-se-á às conciliações e às mediações extrajudiciais a tabela referente ao menor valor cobrado na lavratura de escritura pública sem valor econômico (artigo 36). Ultrapassados os 60 minutos, serão cobrados emolumentos proporcionais ao tempo excedido, ou então o valor integral relativo a cada nova sessão. Esses valores poderão ser rateados entre as partes, que também poderão dispor de modo diverso (artigo 36).

Levando em consideração as desistências das partes envolvidas antes do acontecimento das sessões, Cabral (2018), analisando o provimento no 67/2018 do CNJ, afirma que "pode acontecer o arquivamento do requerimento e nessa hipótese, será restituído ao requerente $75 \%$ do valor pago, com exceção das despesas de notificação, salvo se ocorrer a desistência do pedido antes da realização do ato (artigo 38)".

Outro ponto importante e verificado por Cabral (2018) é de que:

Os serviços notariais e de registros também deverão fazer sessões de conciliação e de mediação não remuneradas para atender às demandas de gratuidade, como contrapartida da autorização para prestar o serviço, no percentual estabelecido pelo tribunal respectivo (artigo 39).

Nesse momento é importante observar os argumentos trazidos por Trícia Cabral (2018) em referência especificamente aos emolumentos dos cartórios extrajudiciais:

Os emolumentos das conciliações e mediações devem corresponder ao efetivo custo e à adequada remuneração dessa nova atribuição. Isso porque a natureza pública das atividades notariais e registrais está ligada ao dever do Estado de proporcionar meios econômicos

RC: 87863

Disponível em: https://www.nucleodoconhecimento.com.br/sem-categoria/conciliacao-e$\underline{\text { mediacao }}$ 
necessários ao exercício de novas atribuições, garantindo a qualidade do serviço público pela fixação de remuneração que seja correspondente ao seu efetivo custo.

Essa sistemática permitiria maior adesão das serventias extrajudiciais aos meios consensuais, sobretudo daquelas deficitárias. Certamente, não é o que ocorrerá.

Por outro lado, foi contemplada a desvinculação dos emolumentos ao acordo, afastando atuações errôneas e resultados equivocados. Nesse ponto, andou bem o provimento.

Ainda seguindo a atuação das câmaras privadas, nas serventias extrajudiciais os emolumentos devem ser considerados por hora de atuação e assim foi disciplinado no parágrafo $2^{\circ}$ do artigo 36 do Provimento 67/2018.

\subsection{DISPARIDADES ESTATAIS OCASIONADAS PELA APLICAÇÃO DA REGRA DA GRATUIDADE DA JUSTIÇA}

O benefício da gratuidade de justiça é amparado no Código de Processo Civil de 2015 e compreende os emolumentos gerados pelas práticas cartorárias. Em conformidade:

Art. 98. A pessoa natural ou jurídica, brasileira ou estrangeira, com insuficiência de recursos para pagar as custas, as despesas processuais e os honorários advocatícios têm direito à gratuidade da justiça, na forma da lei.

$\S 1^{\circ}$ A gratuidade da justiça compreende:

$(\ldots)$

IX - Os emolumentos devidos a notários ou registradores em decorrência da prática de registro, averbação ou qualquer outro ato notarial necessário à efetivação de decisão judicial ou à continuidade de processo judicial no qual o benefício tenha sido concedido.

Acontece que mesmo tendo essa especificidade de cobertura da gratuidade de justiça vir expressa no CPC/2015 acontecem disparidades estatais em sua aplicação tanto para aceitá-la quanto para afastá-la e de acordo com Trícia Cabral (2018) existem razões para o afastamento da gratuidade trazida nos parágrafos $1^{\circ}$ e $2^{\circ}$ do art. 169 amparado no mesmo Código Processual Civil. Vejamos:

RC: 87863

Disponível em: https://www.nucleodoconhecimento.com.br/sem-categoria/conciliacao-e$\underline{\text { mediacao }}$ 
A gratuidade, enquanto o $\S 1^{\circ}$ do artigo 169 do CPC/15 autoriza a realização de conciliações e a mediações, voluntariamente, observada a legislação pertinente e a regulamentação do tribunal, a Lei de Mediação não prevê a voluntariedade nem mesmo dos mediadores judiciais. Já o $\S 2^{\circ}$ do artigo 169 do CPC/15 dispõe que os tribunais determinarão o percentual de audiências não remuneradas que deverão ser suportadas pelas câmaras privadas de conciliação e mediação, com o fim de atender aos processos em que haja sido deferida gratuidade da justiça.

Quanto a possibilidade de disparidade entre os Estados em relação a gratuidade de justiça, Cabral (2018), complementa:

No caso das serventias extrajudiciais, ficou determinado que poderão realizar sessões não remuneradas em percentual a ser fixado pelos tribunais não inferior a $10 \%$ do total semestral de sessões (parágrafo único, artigo 39, Provimento 67/2018). Embora essa regra afaste a concessão ampla e indiscriminada da gratuidade, seria mais adequado estabelecer tanto mínimo quanto máximo a ser fixado, evitando disparidades entre os Estados.

Importante salientar que, discordamos das ideias de afastamento da gratuidade de justiça trazidas por Cabral (2018), já que sua abrangência já vinha expressa no artigo $3^{\circ}$ da Lei $n^{\circ} 1.060$ e em alguns provimentos gerais de Corregedorias estatais e do Distrito Federal e em vasta jurisprudências estaduais, distritais e do STJ, bem antes da regência do CPC de 2015, da Lei de Mediação 13.140 e do próprio provimento $67 / 2018$ do CNJ em estudo.

Como exemplo consubstanciado para a ideia de que a conciliação/mediação cartorária pode ser abarcada pela gratuidade de justiça podemos trazer a ocorrida no julgamento do Agravo de Instrumento № 20150020013680AGI pela 4ª Turma Cível do Fórum de Brasília. Vejamos os trechos decisórios a seguir:

Aos atos extrajudiciais praticados por notários e registradores serão estendidos os benefícios da gratuidade de justiça relacionados à efetividade do processo judicial.

Não há dúvida, portanto, de que a assistência judiciária gratuita contempla atos notariais e de registro indispensáveis ao desenvolvimento da relação processual.

RC: 87863

Disponível em: https://www.nucleodoconhecimento.com.br/sem-categoria/conciliacao-e$\underline{\text { mediacao }}$ 


\title{
4.8 NECESSIDADE DE ESPAÇO PRÓPRIO E DE TRIAGEM PRÉVIA
}

Cabral (2018, p. 3) ao analisar o provimento esmiúça-se a necessidade de criação de espaço próprio e de triagem prévia para atuação da função de conciliação/mediação nas serventias extrajudiciais. Assim, reporta-se, de acordo com o artigo 21 do Provimento 67/2018. Citamos:

\begin{abstract}
Na data e hora designadas, será feito o chamamento das partes e, na ausência de qualquer uma delas, o requerimento será arquivado, exceto nas hipóteses do parágrafo $2^{\circ}$, do artigo 21 . Obtido o acordo, 0 termo será arquivado em livro próprio e terá força de título executivo extrajudicial, nos termos do artigo 784, IV, do CPC (artigo 22). O requerente também poderá desistir, a qualquer tempo, do requerimento, que será arquivado independentemente da anuência da parte contrária (artigo 24).
\end{abstract}

Resta que em relação aos cartórios grandes não existe dificuldade nessa questão, a dificuldade surgirá nos cartórios pequenos.

\subsection{VEDAÇÕES DE CLÁUSULA COMPROMISSÓRIA DE CONCILIAÇÃO E MEDIAÇÃO}

Com o intuito de proteger a captação indireta de possíveis clientes o provimento 67/2018 traz expresso em seu bojo, de acordo com Trícia Cabral (2018), o impedimento de qualquer documento produzido pelos cartórios trazer uma cláusula compromissória de conciliação/mediação expressa. Percorremos:

O artigo 40 do provimento dispõe sobre a vedação de os serviços notariais e de registro estabelecerem, em documentos por eles expedidos, cláusula compromissória de conciliação ou de mediação extrajudicial. Trata-se de medida que visa evitar a captação indireta de serviços de conciliação e de mediação, além de eventualmente comprometer a autonomia privada das partes quanto à escolha voluntária por essas vias de solução de conflito.

Como podemos perceber da análise textual do trecho trazido por Cabral (2018), além de expressar sobre proibição da captação indireta reporta a necessidade de 
cumprimento dos mandamentos sobre o princípio basilar da autonomia de vontades, necessário para que os mecanismos resolutivos de conflitos funcionem de uma maneira mais efetiva.

\section{CONSIDERAÇÕES FINAIS}

Os processos que chegam ao judiciário, em sua grade maioria, são produtos de conflitos que foram construídos (em espiral) por motivos diversos. Quando as partes optam pela mediação/conciliação nas serventias extrajudiciais, presume-se que estejam abertas ou desejosas de resolver aquela situação de forma menos dolorosa ou demorada e convencionada através da autonomia de vontade dos envolvidos, ou seja, consensual ou amigável.

Portanto, importante destacar qualquer iniciativa que aumente a eficiência, eficácia e efetividade dos mecanismos resolutivos de conflitivos. Ademais, a capilaridade das serventias extrajudiciais com a inclusão de cartórios que lidam com os conflitos da comunidade de uma forma bastante direta é um ganho sem precedentes.

Acontece que, da maneira como foi apresentado amplamente esmiuçado, o provimento № 67/2018 com a implementação dos serviços nas serventias extrajudiciais, acontecerá de forma desigual pelo território nacional e isso dificultará a atuação dos facilitadores capacitados, enxergando como um problema global e não pontual.

Outro ponto diz respeito à mitigação do princípio da confidencialidade, já que a obrigatoriedade de registros nos livros trazida pelo provimento № 67/2018 não delimita quem terá acesso a tal documentação e, como os registros ficarão sob a guarda dos cartórios não se enxerga a delimitação de diligência extrajudicial para poder pedir a apresentação e ficou em aberto a questão de quem irá poder ter acesso a esses registros.

RC: 87863

Disponível em: https://www.nucleodoconhecimento.com.br/sem-categoria/conciliacao-e$\underline{\text { mediacao }}$ 
Os órgãos de serventia pública são propensos a uma atividade híbrida de função pública e privada e, certamente, com a implantação do provimento № 67/2018, também poderá se agravar, já que, peca quando prevê representação por procuração, onde sua regulamentação ficou confusa, misturando instituto de mediação judicial com o da extrajudicial.

A falta de equiparação salarial entre os conciliadores/mediadores ad hocs, de câmaras privadas e os das serventias extrajudiciais também é um ponto que deve ser revisto para adequações futuras.

Outras controvérsias também foram objeto desse estudo que teve como objetivo principal a explanação das dúvidas surgidas com a implementação do provimento № $67 / 2018$.

Espera-se, por fim, que o material possa contribuir para formação e informação de todos aqueles que tenham interesse em se dedicar a conciliação/mediação nas serventias extrajudiciais. como prática facilitadora e corriqueira do seu cotidiano, seja profissional como pessoal.

\section{REFERÊNCIAS}

ANDRADE, Paula. Cartórios poderão oferecer serviços de mediação e conciliação judicial. Agência CNJ de Notícias, Brasília, 28 mar. 2018. Disponível em: https://www.cnj.jus.br/noticias/cnj/86416-cartorios-poderao-oferecer-servico-demediacao-e-conciliacao-judicial. Acesso em: 28 Jul. 2019.

BRASIL. Lei № 13.105, de 16 de março de 2015. Código de Processo Civil. 2015b. Disponível em: http://www.planalto.gov.br/ccivil_03/_Ato20152018/2015/Lei/L13105.htm. Acesso em: 26 mar. 2019.

BRASIL. Lei № 13.140, de 26 de junho de 2015. Dispõe sobre a mediação entre particulares como meio de solução de controvérsias e sobre à autocomposição de RC: 87863

Disponível em: https://www.nucleodoconhecimento.com.br/sem-categoria/conciliacao-emediacao 
conflitos no âmbito da administração pública; altera a Lei no 9.469, de 10 de julho de 1997, e o Decreto no 70.235, de 6 de março de 1972; e revoga o $\S 20$ do art. 60 da Lei no 9.469, de 10 de julho de 1997. 2015c. Disponível em: http://www.planalto.gov.br/ccivil_03/_ato2015-2018/2015/lei//13140.htm. Acesso em: 29 jul. 2019.

BRASIL. Lei № 8.935, de 18 de novembro de 1994. Regulamenta o art. 236 da Constituição Federal, dispondo sobre serviços notariais e de registro. (Lei dos cartórios). Disponível em: http://www.planalto.gov.br/ccivil_03/leis/L8935.htm. Acesso em: 12 jul. 2019.

CABRAL, Trícia Navarro Xavier. Permitir que os cartórios façam conciliação e mediação é iniciativa bem vinda. Consultor Jurídico: Opinião. Disponível em:

https://www.conjur.com.br/2018-abr-05/tricia-navarro-permitir-conciliacaocartorios-medida-bem-vinda\#author; em Conhecimento além da sala de aula: 06/04/2018 (profpatriciadonzele.blogspot.com); em: Artigo "Permitir que cartórios façam conciliação é iniciativa bem-vinda" por Trícia Cabral - ANOREG e SERJUS ANOREG/MG - Associação dos Notários e Registradores do Estado de Minas Gerais; em: Opinião: Permitir que cartórios façam conciliação e mediação é iniciativa bemvinda | Anoreg/MT (anoregmt.org.br) e em: Artigo: "Permitir que cartórios façam conciliação e mediação é iniciativa bem-vinda" - por Trícia Navarro Xavier Cabral 09/04/2018 - CNB-SP (cnbsp.org.br). Acesso em: 07 de junho de 2021.

COELHO, Washington Souza e BONATO, Giovanni. A mediação no contexto atual: Um caminho para o diálogo transdisciplinar. Revista de Formas Consensuais de Solução de Conflitos. Organização Comitê Científico. Double Blind Review pelo SEER/OJS. Disponível em: https://www.indexlaw.org/index.php/revistasolucoesconflitos/article/download/4442/p $d f+\& c d=7 \& h l=p t-B R \& c t=c l n k \& g l=b r$. Acesso em: 5 jun. 2021. 
CONSELHO NACIONAL DAS INSTITUIÇÕES DE MEDIAÇÃO E ARBITRAGEM. Regulamento Modelo de Mediação. Disponível no endereço eletrônico: http://www.conima.org.br/regula_modmed. Consulta realizada em 27/07/2019.

CONSELHO NACIONAL DE JUSTIÇA. Provimento 67, de 26 de março de 2018. Disponível no endereço eletrônico: http://www.cnj.jus.br/buscaatosadm?documento=3415. Consulta realizada em 27/07/2019.

COURA, Kalleo e PIMENTA, Guilherme. Brasil. 0 país dos bacharéis "doutores". Um em cada dez universitários estuda Direito in O futuro do Direito, 1를 Edição: Cia do e-Book, JOTA, 2017.

COURA, Kalleo e PIMENTA, Guilherme. Brasil. Formado em Direito? Veja 23 carreiras possíveis in O futuro do Direito, 1를 Edição: Cia do eBook, JOTA, 2017.

CRUZ, Luiz Henrique Santos da; SACRAMENTO, ELOIZA MARIA DO. A EFETIVIDADE DA CONCILIAÇAO E DA MEDIAÇÃO EXTRAJUDICIAL COMO INTRUMENTOS DE PACIFICAÇÃO SOCIAL, SOLUÇÃO E PREVENÇÃO DE CONTROVERSIAS. Disponível em: https//www.even3.com.br/anais/spic/122404-aefetividade-da-conciliacao-e-da-mediacao-extrajudicial-como-intrumentos-depacificacao-social-solucao-e-preven. Acesso em: 30/07/2019.

FEIGELSON, Bruno. Advocacia 2.0: Como advogar no século $\mathbf{X X}$ in $\mathrm{O}$ futuro do Direito, 1를 Edição: Cia do e-Book, JOTA, 2017.

HILL, Flávia Pereira. Mediação nos Cartórios extrajudiciais: desafios e perspectivas. Revista Eletrônica de Direito Processual - REDP. Rio de Janeiro. Ano 13. Volume 19. Número 13. Setembro a Dezembro de 2018. https://www.epublicacoes.uerj.br/index.php/redp/article/view/39175/27450. Consulta realizada em 28/07/2019. 
MIRANDA, Maria Bernadete. Aspectos Relevantes do Instituto de Mediação no Mundo e no Brasil. Revista virtual Direito Brasil. Volume 6 - Número 2, 2012. Disponível em: https://irp.cdn-website.com/951f8786/files/uploades/v62art5.pdf. Acesso em: 05 jun.2021.

MOLOGNI, Celina Kazuko Fujioka. Resolução dos conflitos familiares através da mediação e acesso à justiça. UNOPAR Cient., Ciênc. Juríd. Empres., v.4, n.1/2, p. 35-42, mar./set. 2003. Disponível em: Resolução dos conflitos familiares através da mediação como categoria de acesso à justiça = Solution for family conflicts through mediation and access to justice (researchgate.net). Acesso em: 05 jun. 2021.

MORAES, Tiago França. A mediação, a conciliação e a arbitragem como formas alternativas de resolução de conflitos. Revista Jus Navigandi, ISSN 1518-4862, Teresina, ano $17, \mathrm{n}$. 3346, 29 ago. 2012.

Disponível em: https://jus.com.br/artigos/22520. Acesso em: 5 jun. 2021.

MOREIRA, Katia Denise. A Mediação como método de resolução de conflitos interpessoais na Universidade Federal de Santa Catarina. Trabalho de Conclusão de Mestrado Profissional em Administração Universitária da Universidade Federal de Santa Catarina, Florianópolis, SC, 2012, p. 274.

NADER, Laura. The ADR explosion: the implications of rhetoric in legal reforms. Windsor Yearbook of Access to Justice, Ontário, v. 8, p. 269-291, 1988.

PEDROSO, Alberto Gentil de Almeida. A Conciliação e a Mediação no Serviço Extrajudicial - Breves Ponderações sobre o Provimento № 67/2018. Registrando o Direito. Ano 02 - edição 04 - Maio/Junho de 2018. Disponível em: registrando-odireito-novembro-lucas.indd (infographya.com). Acesso em: 07.Jun. 2021.

PIQUET, Helène. A Mediação popular na China: acesso à justiça ou harmonia imposta? Meritum. Belo Horizonte. V. 7. N.2. p. 141-180, jul.dez. 2012. 
SERPA, Maria de Nazaré. Teoria e prática da mediação de conflitos. Rio de Janeiro: Lumen Juris. 1999.

SPENGLER, Fabiana Marion. Mediação de conflitos: da teoria à prática. $2^{\underline{a}}$ Ed, Porto Alegre, Livraria do Advogado, 2017.

SIX, Jean François. Dinâmica da Mediação. Tradução Giselle Groeninga de Almeida, Águida Arruda Barbosa e Eliana Riberti Nazareth. Belo Horizonte: Del Rey, 2001.

VILHENA, Oscar. Prefácio: A revolução no mundo de Cícero in O futuro do Direito, 1ํㅡㄹição: Cia do eBook, JOTA, 2017.

ZENKER, Anna Cristina; SILVA, Juvêncio Borges. Acesso à justiça pela atuação profilática do tabelião: a mediação extrajudicial como meio alternativo de solução de conflitos. Scientia luris, Londrina, v. 22, n. 3, p. 88-110, nov. 2018. DOI: 10.5433/2178-8189.2018v22n3p88. ISSN: 2178-8189.

\section{APÊNDICE - REFERÊNCIA DE NOTA DE RODAPÉ}

3. Cadastro de Cartório do Brasil (mj.gov.br)

Enviado: Junho, 2021.

Aprovado: Junho, 2021. 